(NASA-TH-X-71694) : STRESS ANALYSIS AND

N75-21670)

STRESS INTENSITY FACTORS FOR FINITE GEOMETRY

SOLIDS CONTAINING RECTANGULAR SURFACE CRACKS

(NASA) $31 . \mathrm{g}$ HC $\$ 3.75$

CSCL $20 \mathrm{~K}$

G $3 / 39 \quad 18653$

\title{
STRESS ANALYSIS AND STRESS INTENSITY FACTORS FOR FINITE GEOMETRY SOLIDS CONTAINING RECTANGULAR SURFACE CRACKS
}

by John P. Gyekenyesi and Alexander Mendelson

Lewis Research Center

Cleveland, Ohio 44135

TECHNICAL PAPER to be presented at Winter Annual Meeting of the American Society of Mechanical Engineers Houston, Texas, November 30-December 5, 1975

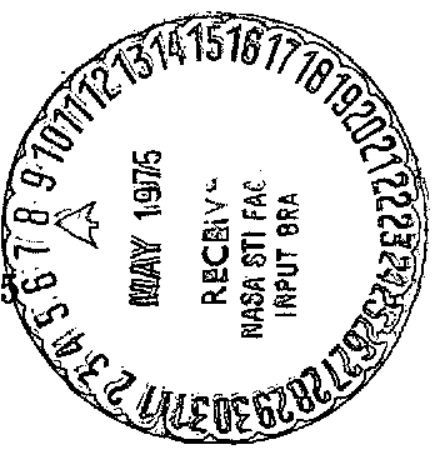


STRESS ANALYSIS AND. STRESS INTENS ITY FACTORS FOR . FINITE...

GEOMETRY SOLIDS CONTAINING RECTANGULAR SURFACE CRACKS

by John P. Gyekenyesi and Alexander Mende1son

National Aeronautics and Space Administration

Lewis Research Center

Cleveland, Ohio 44135

\section{SUMMARY}

The line method of analysis is applied to the Navier-Cauchy equations of elastic equilibrium to calculate the displacement field in a finite geometry bar containing a variable depth rectangular surface crack under extensionally applied uniform loading. The application of this method to these equations leads to coupled sets of simultaneous ordinary differential equations whose solutions are obtained along sets of lines in a discretized region. Using the obtained displacement field, normal stresses and the stress intensity factor variation along the crack periphery are calculated for different crack depth to bar thickness ratios. Crack opening displacements and stress intensity factors are also obtained for a through-thickness, center cracked bar with variable thickness. The reported results show a considerable potential for using this method in calculating stress intensity factors for commonly encountered surface crack geometries in finite solids.

\section{INTRODUCTION}

The main goal of fracture mechanics is the prediction of the load at which a structure weakened by a crack will fail. Knowledge of the stress and displacement distributions near the crack tip is of fundamental importance in evaluating this load at failure. During the early development of crack mechanics most of the effort was focused on through- 
thickness cracks which could be characterized as two-dimensional. However, part-through cracks are the most common type of crack defect found in actual service conditions (ref. 1).

Because of 1ts inherent three-dimensional character, only limited analytical work has been done in the past on surface crack problems. Early theoretical solutions, for surface flaw problems usually involved. the discussion of semi-circular or semi-elliptical cracks in semi-infinite solids (refs. 2 to 8 ). For this reason, results for finite geometry stress intensity factors are usually reported in terms of magnification factors applied to some convenient reference solution (ref. 9). These correction factors are then to account for certain inherent finite dimensions of the problem at hand. However, due to the formidable task involved in obtaining solutions for semi-infinite solids, only the front and back face magnification factors have been successfully calculated in the past, with little consideration given to the finite length or width normally encountered in engineering applications. In addition, considerable scatter exists in the reported results as obtained. by different investigators (ref. 9).

Recently, approximate solutions of the finite geometry surface crack problem were obtained by the boundary integral equation method (ref. 10) and the finite element method (ref. 11). These solutions, however, have serious limitations since for acceptable accuracy in threedimensional problems, the number of elements needed is extremely large, taxing even today's computers.

An alternate semi-analytical method suitable for the elastic solution of the surface crack problem is the line method of analysis. Successful 
application of this method to finite geometry solids containing cracks has been demonstrated by Gyekenyesi and Mendelson (ref. 12). Although the concept of the Iine method for solving partial differential- equations is not new (ref. 13), its application in the past has been limited in the analysis of solids and structures.

It is the purpose of this report to present a simple and straightforward approach to the elastic analysis of the finite geometry surface crack problem. Since the first treatment of this problem by Irwin in 1962, considerable analytical effort has been expanded towards the development of an acceptable solution, but progress to this end has been slow and limited. In this report, the line method of analysis is extended to part-through rectangular cracks in bars of finite dimensions under normal tensile loadings. Results are obtained for various crack depth to bar thickness ratios and effects of variable bar length and thickness on crack opening displacements are summarized. REDUCTION OF THE NAVIER-CAUCHY EQUATIONS TO SYSTEMS OF ORDINARY DIFFERENTIAL EQUATIONS

Within the framework of linearized elasticity theory, the equations of elastic equilibrium in terms of displacements are

$$
\begin{aligned}
& (\lambda+G) \frac{\partial e}{\partial x}+G \nabla^{2} u=0 \\
& (\lambda+G) \frac{\partial e}{\partial y}+G \nabla^{2} v=0 \\
& (\lambda+G) \frac{\partial e}{\partial z}+G \nabla^{2} w=0
\end{aligned}
$$


where the body forces are assumed to be zero and the dilatation is

$$
e=\frac{\partial u}{\partial x}+\frac{\partial v}{\partial y}+\frac{\partial w}{\partial z}
$$

For a finite geometry solid with rectangular boundaries we construct three sets of parallel lines (fig. 1(a)). Each set of lines is parallel to one of the coordinate axes and thus perpendicular to the corresponding coordinate plane. An approximate solution of equation (1) can then be obtained by developing solutions of ordinary differential equations along the $x$-directional lines. As seen in the figure, there are a total of $\ell=N Y \times N Z$ such lines were $N Y$ is the number of lines along the $\mathrm{y}$-direction and NZ is the number of lines along the z-direction in a given plane, respectively. We define the displacements along these lines as $u_{1}, u_{2}, \ldots, u_{\ell}$. The derivatives of the y-directional displacements on these lines with respect to y are defined as $\left.v^{\prime}\right|_{1},\left.v^{\prime}\right|_{2}, \ldots$, $\left.v^{\prime}\right|_{\ell}$, and the derivatives of the z-directional. displacements with respect to $z$ are defined as $\left.w^{\prime}\right|_{1},\left.w^{\prime}\right|_{2}, \ldots .,\left.w^{\prime}\right|_{\ell}$. These displacements and derivatives can then be regarded as functions of $x$ only since they are variables on $x$-directional lines. When these definitions are used, the ordinary differential equation along a generic line ij (a double subscript is used here for simplicity of writing) in figure $1(b)$ may be written as 


$$
\begin{aligned}
& \frac{d^{2} u_{i j}}{d x^{2}}+\frac{(1-2 v)}{2(1-v)}\left[-\left(\frac{2}{h_{y}^{2}}+\frac{2}{h_{z}^{2}}\right) u_{i j}+\frac{1}{h_{y}^{2}}\left(u_{i+1, j}+u_{i-1, j}\right)\right. \\
& \left.+\frac{1}{h_{z}^{2}}\left(u_{i, j+1}+u_{i, j-1}\right)\right]+\frac{f_{i j}(x)}{2(1-\nu)}=0
\end{aligned}
$$

where

$$
\begin{aligned}
& f_{i j}(x)=\left.\frac{d v^{\prime}}{d x}\right|_{1 j}+\left.\frac{d w^{\prime}}{d x}\right|_{i j} \\
& v^{\prime}=\frac{d v}{d y}
\end{aligned}
$$

and

$$
w^{\prime}=\frac{d w}{d z}
$$

Similar differential equations are obtained along the other $x$-directional lines. Since each equation has the terms of the displacements on the surrounding lines, these equations constitute a system of ordinary differential equations for the displacements $u_{1}, u_{2}, . ., u_{\ell}$.

The set of $\ell$ second order differential equations represented by (5) can be reduced to a set of $2 l$ first order differential equations by treating the derivatives of the u's as an additional set of $\ell$ unknowns, i.e. defining

$$
u_{\ell+1}=\frac{d u_{1}}{d x}, u_{\ell+2}=\frac{d u_{2}}{d x}, \text { etc. }
$$


The resulting $2 l$ equations can now be written as a singlè first order matrix differential equation

$$
\frac{d U}{d x}=A_{1} U+R(x)
$$

where $U$ and $R$ are column matrices of $2 \ell$ elements each and $A_{I}$ is a $2 l \times 2 l$ matrix of the constant coefficients appearing in equations (5) and (7).

In a similar manner, to solve equations (2) and (3) ordinary differential equations are constructed along the $y$ - and $z$-directional lines respectively. These equations are also expressed in an analogous form to equations (8); they are

$$
\begin{aligned}
& \frac{d V}{d y}=A_{2} V+S(y) \\
& \frac{d W}{d z}=A_{3} W+T(z)
\end{aligned}
$$

Equations (8) to (10) are linear first-ordex ordinary matrix differential equations. They are; however, not independent, but are coupled through the vectors $R, S$ and $T$ whose components are given by equations similar to (6). The elements of the coefficient matrices $A_{1}$, $A_{2}$ and $A_{3}$ are all constants, being functions of the coordinate increments and Poisson's ratio only.

Noting that a second-order differential equation can satisfy only a total of two boundary conditions and since three-dimensional elasticity problems have three boundary conditions at every point of the bounding 
surface, some of the boundary data must be incorporated into the surface line differential equations. Hence; conditions of normal stress and... displacement are enforced through the constants of the homogeneous solutions while shear stress boundary data must be incorporated into the differential equations of the surface lines. The application of the specified shear conditions permits the use of central difference approximations when surface line differential equations are constructed. The details of constructing these equations are found in reference 14 . SOLUTION OF THE SYSTEMS OF ORDINARY DIFFERENTIAI EQUATIONS The systems of ordinary differential equations (8) to (10) can be solved by any of a number of standard techniques. The method used herein was basically the matrizant or Peano-Baker method of integration (ref. 15). For equation (8) the solution can be written as

$$
U(x)=e^{A_{1} x} U(0)+e^{A_{1} x} \int_{0}^{x} e^{-A_{1} n} R(n) d n
$$

with similar solutions for equations (9) and (10). U(0) is the initial value vector, determined from the boundary conditions. The conversion of given boundary data into required initial values is discussed in more detail in reference 14.

The matrizant $e^{A} 1^{x}$ is generally evaluated by its matrix serles. For larger values of $\mathrm{x}$, when convergence becomes slow, additive formulas may be used. In addition similarity transformations can be used to diagonalize the matrix $A_{1}$. These various techniques for improving the accuracy are discussed in detall in reference 14. 
Since equations (8) to (10) and their boundary conditions are highly coupled, it is generally impossible to directly evaluate their solutions. Thus, a successive approximation procedure must be employed where assumed values must be used initially for the required unknowns. The cyclic resubstitution of the obtained solutions into the coupling vectors and the boundary conditions will uswally converge to the correct solution, depending mainly on the accuracy to which the required matrizant can be evaluated.

Once the displacement field in the body has been calculated and the successive approximation procedure has converged, the normal stress distributions can be obtained directly by using the stress-displacement equations. The shear stresses, however, can be evaluated only through fintte difference approximations for the required displacement gradients. NUMERICAL RESULTS

Figure 2 shows a finite geometry bar containing a traction free rectangular surface crack. Because of the symmetric geometry and loading, on1y one-fourth of the bar has to be discretized as shown in figure $2(\mathrm{~b})$. The solution of this problem was obtained by using two different sets of lines along the coordinate axes so that the convergence of the finfte difference approximations could be checked. In a given direction, uniform line spacing was used in all computations although this is not absolutely necessary. In general, an attempt was made to use a finer grid along the direction of largest variable change. The crack edge location with respect to the imposed grid was assumed to be halfway between nodes specifying normal stress and displacement boundary conditions, respectively. 
The successive approximation procedure required for decoupling the three sets of ordinary differential equations was terminated when the difference between successively calculated displacements at every point was less than a preset value $\left(10^{-3}\right)$. As expected, the convergence rate of this successive approximation procedure was greatly dependent on the Initial guess for the required unknowns in the coupling vectors and boundary conditions, For maximum computer efficiency, displacement data obtained from the use of coarse grids was interpolated to obtain Improved starting values for the computations involving the final spacing of lines. The required initial quantitles for the preliminary coarse grid calculations were taken to be zero in our work. All calculations were performed on a UNIVAC 1106 computer, using double precision arithmetic.

Selected results of the dimensionless surface crack opening displacements are shown in figure 3. Note that the crack opening increases rapidly with crack depth for $0.167 \leq \frac{a}{t} \leq 0.834$, slightly exceeding even the surface crack displacement of a through-thickness crack at $\frac{a}{t}=0.834$. The plane strain solution for a finite width center cracked bar is also shown in figure 3 for reference. Final displacement values in this report were obtained from a set of 100,140 and $140 \mathrm{x}, \mathrm{y}$ and $\mathrm{z}$-directional differential equations, respectively.

The maximum crack opening displacement variation with crack depth is shown in figure 4. For shallow cracks, this variation is almost a linear function of crack depth, reaching its maximum value near $\frac{a}{t}=0.90$. Interestingly, for $\frac{a}{t}=1.0$ or a through-thickness crack, the maximum 
crack opening displacement decreases slightly from this critical value.

In order to show the singularity of the stresses, the $y$-directional normal stress in the crack plane is plotted in figure 5 for $\frac{a}{t}=0.5$. The results clearly indicate the singular nature of $\sigma_{y}$ along the crack periphery. Note that in figure $5(\mathrm{a})$, this stress is maximum near the cracked surface of the bar and is minimum at the $z=0$ plane. Figure 5(b), which shows the stress variation along the horizontal edge of the crack, indicates that $\sigma_{y}$ is maximum at $x=0$ and minimum at $x=2.0$.

The variation of crack opening displacement as a function of bar length for a fixed crack geometry is shown in figures 6 and 7. As can be noted from these figures, the finite length of the bar causes a considerable increase in crack displacements for values of $\mathrm{L}<4 \mathrm{c}$. Similar results were obtained in (ref, 12) for a through-thickness, center cracked bar.

\section{STRESS INTENSITY FACTOR}

It is customary in fracture mechanics to describe the plane elasticity crack opening displacement as a superposition of three basic deformation modes (ref. 16). Since the problem shown in figure 2 has geometric symmetry and is symmetrically loaded, only the opening mode of crack displacement is obtained. In terms of the stress intenstity factor for the opening mode' $\mathrm{K}_{\mathrm{I}}$, the plane elasticity crack displacements near the crack tip are given by (ref. 16)

$$
\left.v\right|_{y=0}=\frac{2(1-\nu)}{G} K_{I} \sqrt{\frac{R}{2 \pi}} \quad \text { plane strain. }
$$




$$
\left.v\right|_{y=0}=\frac{2}{(1+\nu) G} K_{I} \sqrt{\frac{R}{2 \pi}} \quad \text { plane stress }
$$

where $R$ here is the distance from the crack edge. Note that $R=z-(t-a)$ along the horizontal edge and $R=(W-c)-x$ along the vertical edge of the crack. Since three-dimensional problems are netther in a state of plane strain nor in"a state of plane stress, the definition of a stress intensity factor for these problems must be first established. Note that by definition the plane stress and plane strain stress intensity factors are equal while the displacements axe approximately 12.5 percent different for $\nu=1 / 3$. Sinçe most published solutions for stress intensity factors are based on plane strain assumptions, equation (12) is selected to calculate the stress intensity factor. Rearranging this equation so that the dimensionless crack opening displacements can be. used leads to

$$
C_{I} K_{I}=\frac{\left.\frac{E v}{\sigma_{0} c}\right|_{y=0}}{\sqrt{\frac{R}{c}}}
$$

where

$$
C_{I}=\frac{4\left(1-\nu^{2}\right)}{\sigma_{0} \sqrt{2 \pi c}}
$$

A plot of equation $(14)$ as $\sqrt{\mathrm{R} / \mathrm{c}} \rightarrow 0$ can then be used to calculate $\mathrm{K}_{\mathrm{I}}$. Since the crack opening displacement is a function of both the thickness 
and width variables, the previously defined stress intensity factor varies in both the $x$ and $z$-directions. It should be noted that this description of $\mathrm{K}_{\mathrm{I}}$ is completely arbitrary and that it is questionable If it has any real significance in three-dimensional elasticity problems. However, values of $\mathrm{K}_{\mathrm{I}}$ are presented here so that a comparison is possible with published plane strain solutions (ref. 16).

The stress intensity factor variation along the crack periphery for different crack depths in a given bar is shown in figures 8 to 14. An important conclusion is immediately obvious from the results shown. The point of maximum stress intensity factor for the rectangular surface crack shown in figure 2 is at the end of the semi-major axis or near the surface for all the crack geometries with $\frac{a}{t}>0.25$. Furthermore, the difference between the stress intensity factors at the surface and at the end of the semi-minor axis increases with crack depth, provided that the other dimensions of the problem remain fixed. These results, therefore, indicate that even though the back face approaches the deep edge of the crack, the point of maximum stress intensity factor does not change. It should also be noted that the minimum stress intensity factor is always at the corner of the crack and its change with crack depth is minimal, in contrast to the maximum stress intensity factor which changes about $400 \%$ over the crack depth range investigated.

Figure 15 shows the stress intensity factor variation along the z-direction for the through-thickness, center cracked bar. Note that $\mathrm{K}_{\mathrm{I}}$ is maximum near the surface and the results are symmetric about the center of the bar. Similar results were obtained in (ref. 12) for a 
somewhat different geometry problem.

A plot of the stress intensity factors at the semi-major and semiminor axes of the crack as a function of crack depth is shown in figure 16. These results indicate that for shallow cracks, $\frac{a}{t} \stackrel{\infty}{<} 0.25$, the stress intensity factor is no longer maximum at the surface but reaches its greatest value at the semi-minor axis. Also note that for deep cracks, the maximum stress intensity factor at the end of the semi-major axis exceeds that obtained for a through-thickness crack. By comparing the results in this report for the rectangular surface crack problem to those of a through-thickness crack in an identical geometry solid, a part through crack correction factor, $C_{f}$ can be obtained for conveniently expressing the calculated maximum stress intensity factor. In terms of this correction factor, let the surface crack results be denoted by

$$
\mathrm{K}_{I_{\mathrm{MAX}}}=\mathrm{C}_{\mathrm{f}}\left(\mathrm{K}_{\mathrm{I}_{\mathrm{T}}}\right)
$$

where $\mathrm{K}_{I_{T}}$ is the maximum stress intensity factor for the through-thickness, center cracked bar. From figure 15 for the geometry in question, $\mathrm{K}_{\mathrm{I}_{\mathrm{T}}}=3.65 \sigma_{\mathrm{o}} \sqrt{\mathrm{c}}$. A plot of $\mathrm{C}_{\mathrm{f}}$ in the above equation as a function of crack depth is shown in figure 17. As expected, $\mathrm{C}_{\mathrm{f}}$ is considerably less than one for shallow cracks, but for deep cracks, $\frac{a}{t}>0.7$, the value of $C_{f}$ exceeds unity.

Since the solution for an elliptical crack in an infinitely large body is readily avaliable and convenient to apply, it is customary in. three-dimensional fracture mechanics to express results for finite geometry 
problems in terms of this solution and suitable magnification factors. The crack opening displacement variation with bar length in figures 6 and 7 can be used to calculate a finite length magnification factor for the selected crack geometry shown in figure 11. A plot of equation (14), as the bar length is increased from $L=1.25$, yields a $7.7 \%$ increase in $K_{I}$ for $I=1.75$, when compared to the infinitely long case. Hence, $M_{\ell}=1.077$ which, by the way, differs considerably from the plane stress finite length correction factor given in (ref. 17) for the through-thickness, central crack problem. Other commonly applied magnification factors are $M_{W}, M_{f}, M_{b}$ and $M_{p}$, where these factors account for finite width, front face, back face and plasticity effects, respectively. Values of these coefficients have been obtained previously. on a limited basis (ref. 9), but direct comparison of these numbers with results in this report is not practical.

A plot of the surface crack opening displacement as a function of bar thickness is shown in figure 18 for a through-thickness, center cracked bar. Note that this displacement increases with increasing bar thickness.

Figure 19 shows the stress intensity factor variation across the bar thickness for the same center cracked bar. Isida's plane strain solution (ref. 17), corrected for finite length and width, is also plotted in this figure. These results indicate that the maximum value of $\mathrm{K}_{\mathrm{I}}$ at the surface remains constant with variation in bar thickness, while at the center of the bar, $\mathrm{K}_{I}$ approaches Isida's plane strain 
solution. However, the obtained minimum value of $\mathrm{K}_{I}$ is about $17 \% \mathrm{~h}$ igher than Isida's result, which would indicate that the plane elasticity finite geometry magnification factors are not equal to those obtained from three-dimensional calculations. It should also be noted that using the calculated displacements in equation (13) rather than equation (12) would result in a $12.5 \%$ lower value of $\mathrm{K}_{\mathrm{I}}$ than that shown in figure 19 . Furthermore, the maximum displacements in figure 18 differ less than $10 \%$ as expected, while for $t=5.5$ in figure $19, \mathrm{~K}_{\mathrm{I}}$ varies from $3.0 \sigma \sqrt{\mathrm{c}}$ to $3.65 \sigma_{\circ} \sqrt{\mathrm{c}}$ or about $22 \%$.

Although the stress intensity factors for these problems could be determined with reasonable accuracy, the associated type of singularities are difficult to evaluate because values of the normal stresses are needed within a distance of $0.05 \mathrm{c}$ or less from the crack edge. With the equal spacing of lines used in these examples, the minimum node location for these problems is about $0.06 \mathrm{c}$. For this range of crack edge distance $R$, the singularity of the stresses is not defined.

\section{CONCLUSIONS}

The line method of analysis presented affords a practical straight forward way for analysis of three-dimensional crack problems, at least for bodies with reasonably regular boundaries. Because parts of the solution are obtained as continuous functions along the lines chosen; relatively good accuracy can be obtained with coarse grids. Results of the analysis include the displacements and normal stresses at every node inside the body from which the stress intensity factor variations were easily calculated. In addition it should be noted that the common 
semi-elliptical surface crack problem could also be analyzed by merely changing the boundary conditions at certain nodes in the crack plane. Introduction of plasticity into the analysis could also be accomplished by changing the coupling terms in equations (8) to (10). Since these have to be determined by an iterative process in any case, it would seem possible to solve the elastoplastic problem by a simple extension of the present method. Whether this approach is practical requires further investigation.

\section{REFERENCES}

1. Srawley, J. E. and Esgar, J. B., "Investigation of Hydrotest Failure of Thiokol Chemical Corporation 260-Inch-Diameter SL-1 Motor Case," NASA TM X-1194, Jan. 1966.

2. Irwin, G. R., "Crack-Extension Force for a Part-Through Crack In a Plate," Journal of Applied Mechan1cs, Vol. 33, Dec. 1962, pp. $651-654$.

3. Smith, F. W., "Stresses Near a Semi-Circular Edge Crack," Ph.D. Thesis, Universtty of Washington, 1966.

4. Smith, F. W. and Alavi, M. J., "Stress Intensity Factors for a Part-Circular Surface Flaw," Proceedings of the First International Pressure Vessel Conference, Holland, 1969.

5. Thresher, R. W. and Smith, F. W., "Stress Intensity Factors for a Surface Crack in a Finfte Solld," Journal of Applied MechanIcs, Vol. 39, Mar. 1972, pp. 195-200.

6. Shah, R. C. and Kobayashi, A. S., "Stress Intensity Factor for an Elliptical Crack Under Arbitrary Normal Loading," Journal of Engineering Fracture Mechanics, Vol. 3, July 1971, pp. 71-96. 
7. Shah, R. C. and Kobayashi, A. S., "On the Surface Flaw Problem," The Surface Crack: Physical Problems and Computational Solutions; Proceedings of the Winter Annual Meeting, New York, American Society of Mechanical Engineers, 1972, pp. 79-124.

8. Hartranft, R. J. and Sih, G. C., "Alternating Method Applied to Edge and Surface Crack Problems," Methods of Analysis and Solutions of Crack Problems: Recent Developments In Fracture Mechanics; Theory and Methods of Solving Crack Problems, LeIden, Noordhoff International Publishing, 1973, pp. 179-238.

9. Keays, R. H., "A Review of Stress Intensity Factors for Surface and Internal Cracks," Australian Defense Scientific Service, Aeronautical Research Laboratories, ARL/SM-Rept-343, 1973.

10. Cruse, T. A., "Numerical Evaluation of Elastic Stress Intenslty Factors by the Boundary-Integral Equation Method," The Surface Crack: Physical Problems and Computational Solutions; Proceedings of the Winter Annual Meeting, New York, American Society of Mechanical Engineers, 1972, Pp. 153-170.

11. Marcal, P. V., "Three-Dimensional Finite Element Analysis for Fracture Mechanics," The Surface Crack: Physical Problems and Computational Solutions; Proceedings of the Winter Annual Meeting, New York, AmerIcan Society of Mechanical Engineers, 1972, pp. 187-202.

12. Gyekenyesi, J. P. and Mendelson, A., "Three-Dimensional Elastic Stress and Displacement Analysis of Finite Geometry Solids Containing Cracks," presented at the Seventh U.S. National Congress of Applied Mechanics, Boulder, Colorado, June 3-7, 1974. 
13. Jones, D. J., South, J. C., and Klunker, E. B., "On the Numerical Solution of Elliptic Partial Differential Equations by the Method of Lines," Journal of Computational Physics, Vol. 9, 1972, pp. 496-527.

14. Gyekenyesi, J. P., "Solution of Some Mixed Boundary Value Problems of Three-Dimensional Elasticity by the Method of Lines," Ph.D. Thesis, Michigan State University, 1972.

15. Frazer, R. A., Duncan, W. J. and Collar, A. R., "Elementary Matrices and Some Applications to Dynamics and Differential Equations," Cambridge University Press, 1938. 16. Paris, P. C. and Sih, G.C., "Stress Analysis of Cracks," Fracture Toughness Testing and Its Applications," STP-381, American Society for Testing and Materials, 1964, pp. 30-83.

17. Isida, M., "Effect of Width and Length on Stress Intensity Factors of Internally Cracked Plates Under Various Boundary Conditions," International Journal of Fracture Mechanics, Vol. 7, Mar. 1971, pp. $301-316$. 


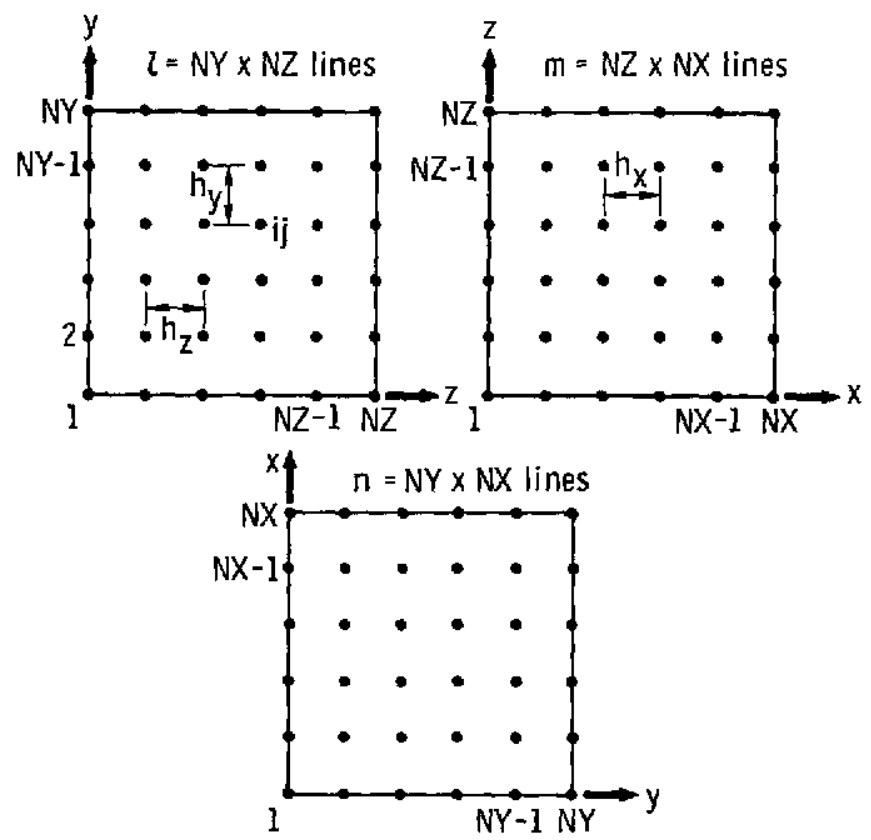

(a) Three sets of lines parallel to $x-, y-$, and $z$-coordinates and perpendicular to corresponding coordinate planes.

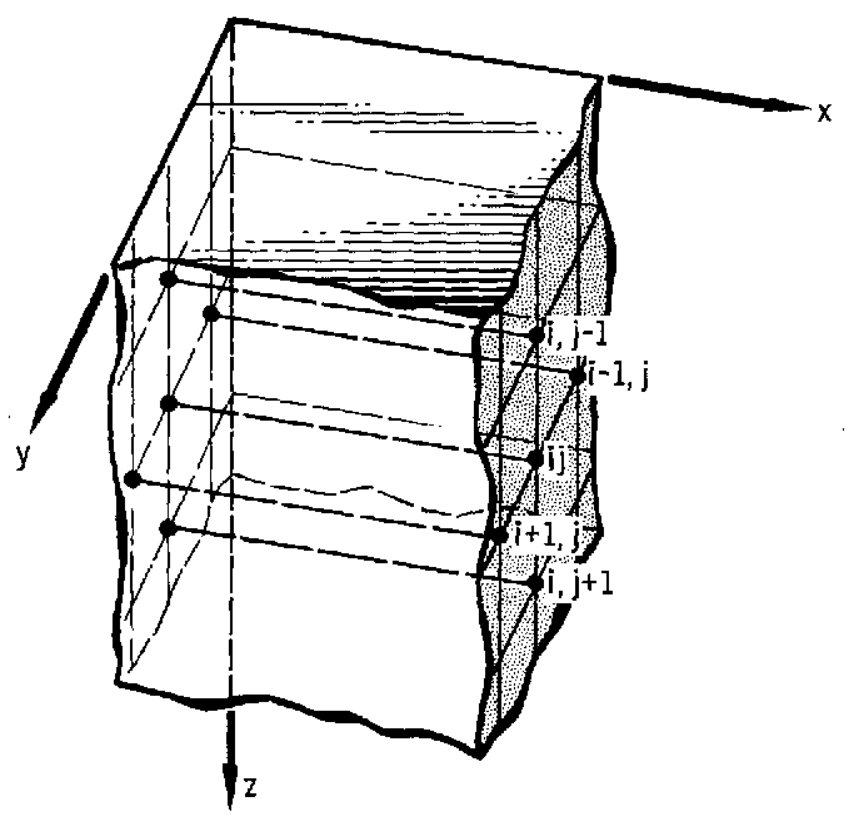

(b) Set of interior lines parallel to $x$-coordinate.

Figure 1. - Sets of lines parallei to Cartesian coordinates. 


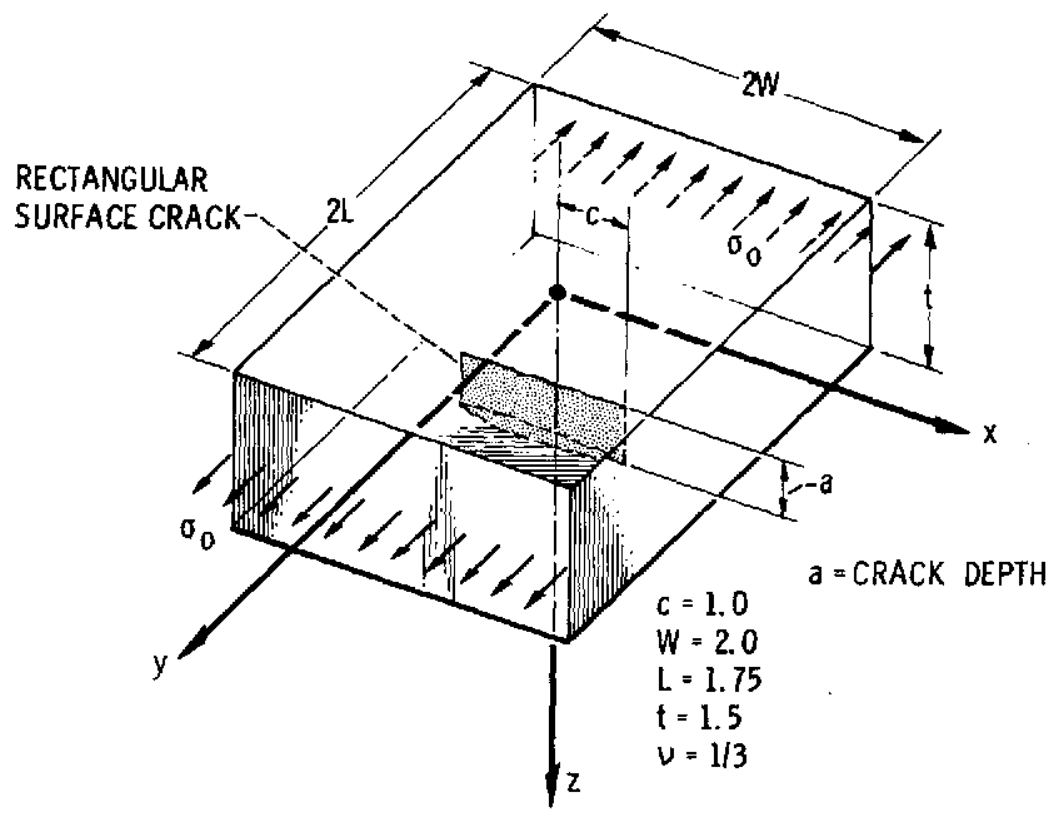

(a) BAR WITH RECTANGULAR SURFACE CRACK.

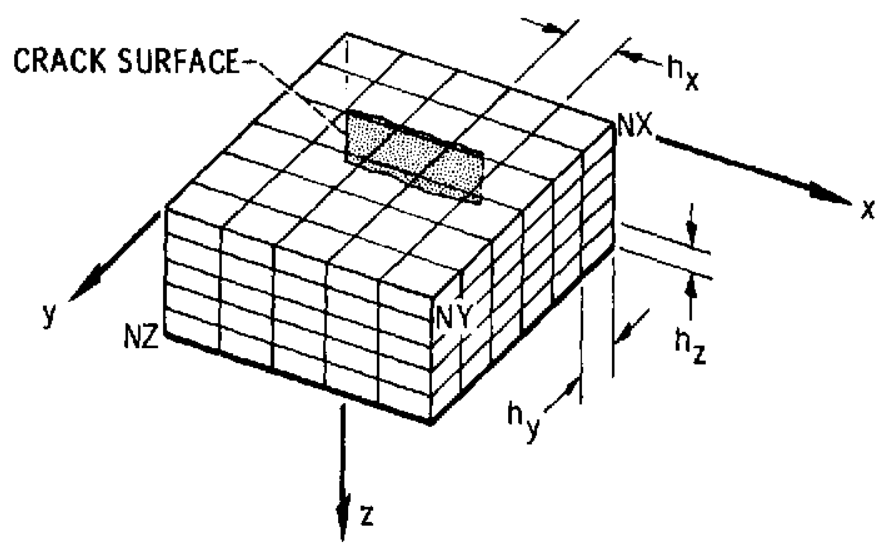

(b) DISCRETIZED REGION OF BAR WITH RECTANGULAR SURFACE CRACK.

Figure 2. - Bar with rectangular surface crack under uniform tension. 


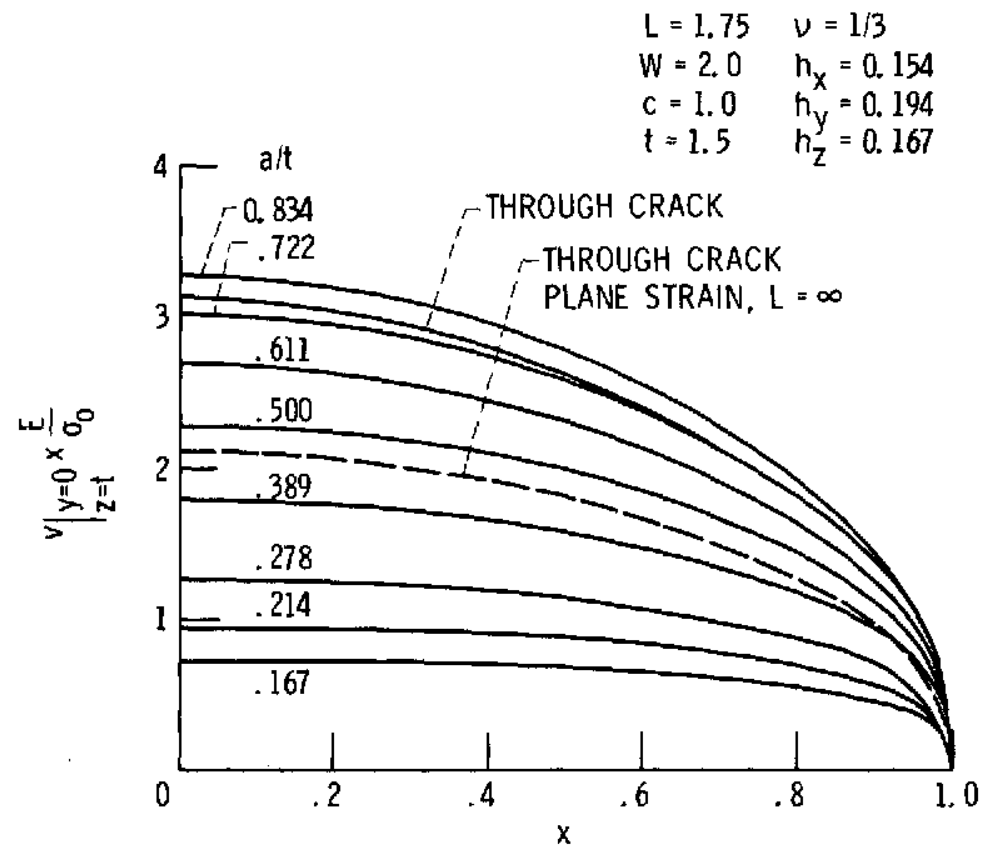

Figure 3. - Surface crack opening displacement variation as a function of crack depth for a rectangular bar under uniform tension.

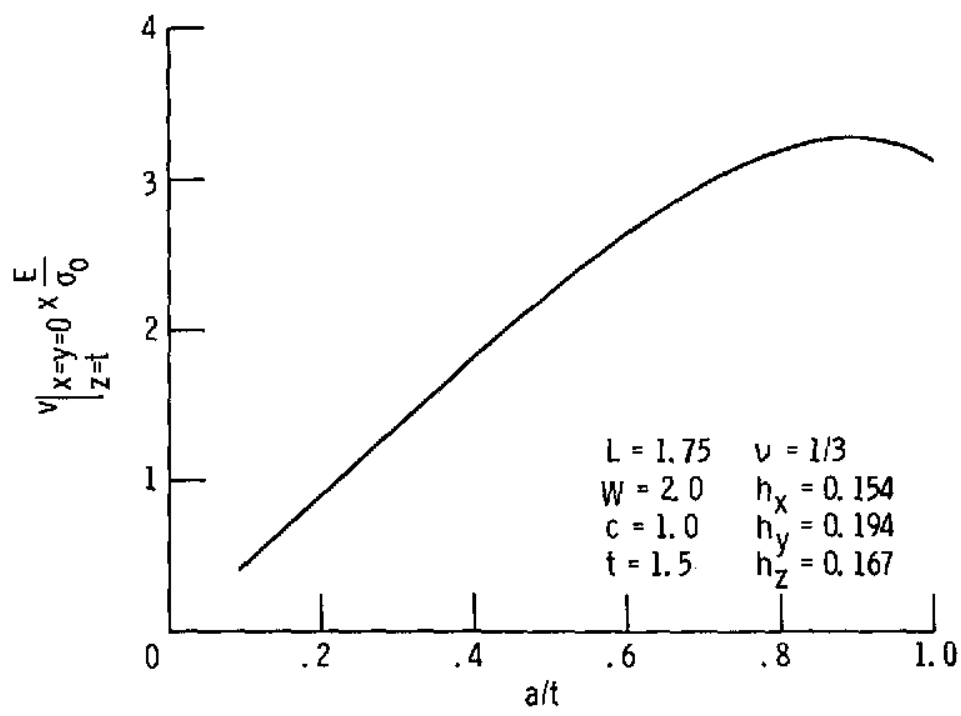

Figure 4. - Maximum crack opening displacement variation with crack depth for a rectangular bar under uniform tension. 


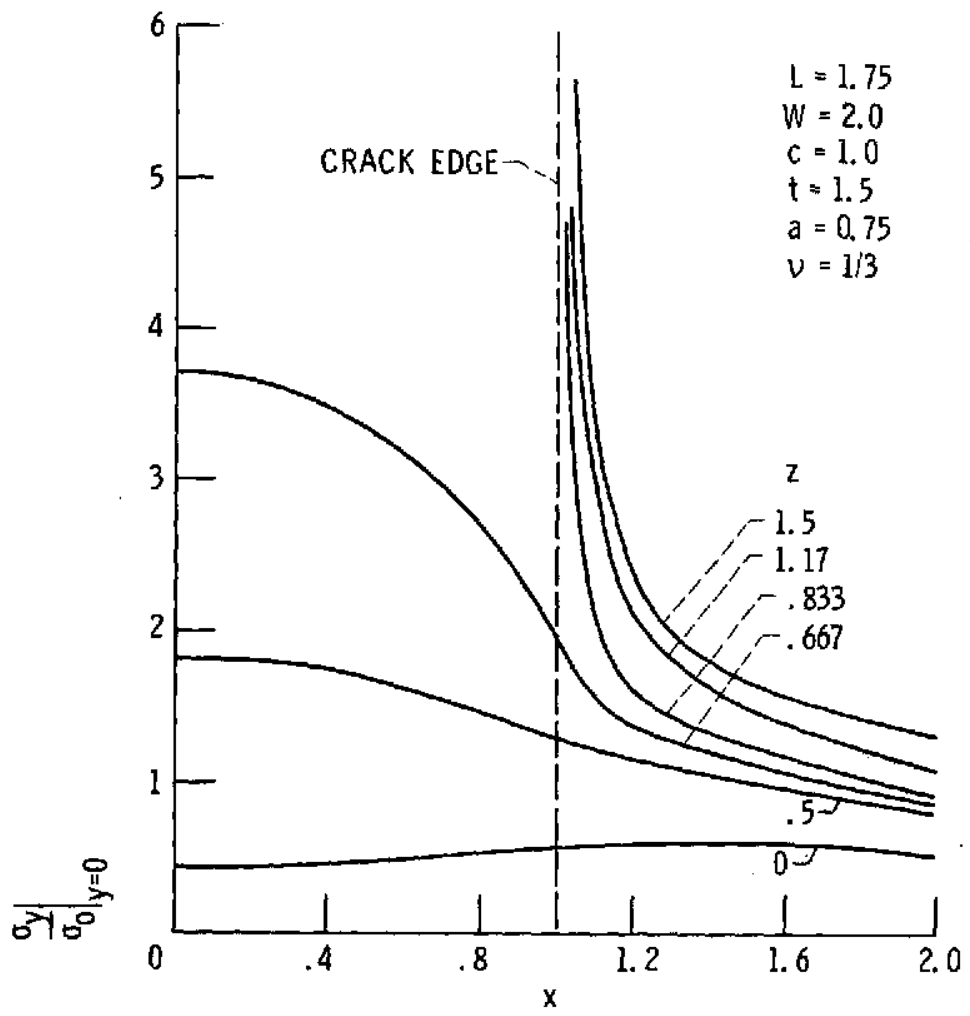

(a) DIMENSIONLESS $y$-DIRECTIONAL NORMAL STRESS VARIATION ALONG BAR WIDTH.

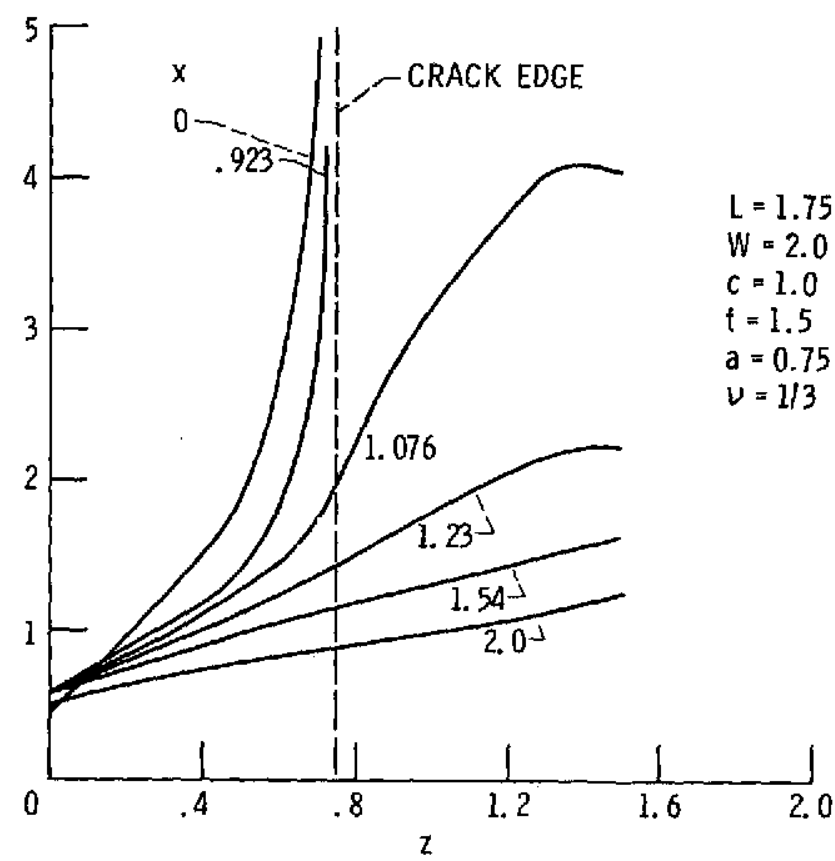

(b) DIMENSIONLESS $y$-DIRECTIONAL NORMAL STRESS VARIATION ACROSS BAR THICKNESS.

Figure 5. - Dimensionless $y$-directional normal stress distribution in the crack plane for a bar under uniform tension containing a rectangular surface crack. 


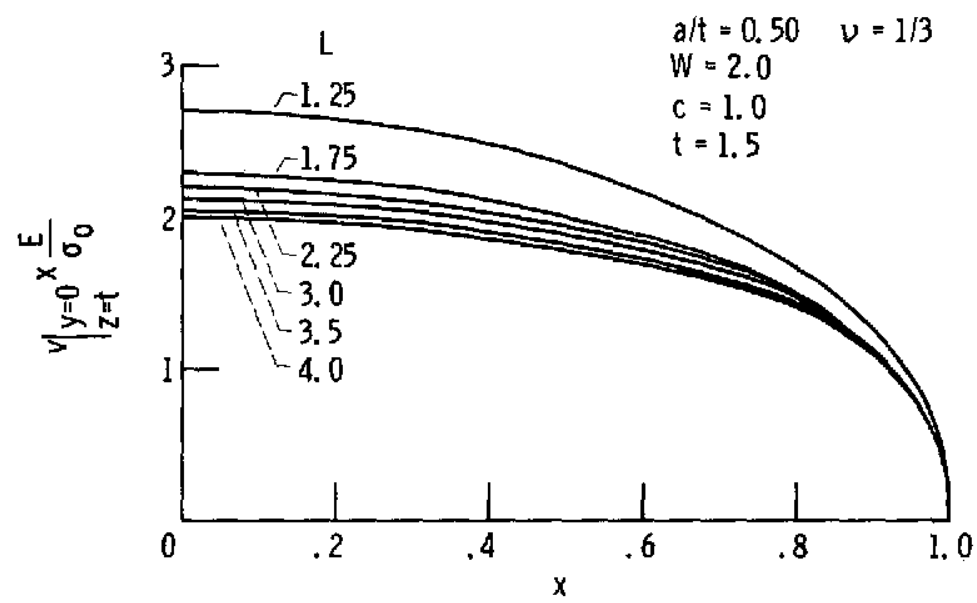

Figure 6. - Surface crack opening displacement variation as a function of bar length for a rectangular bar under uniform tension.

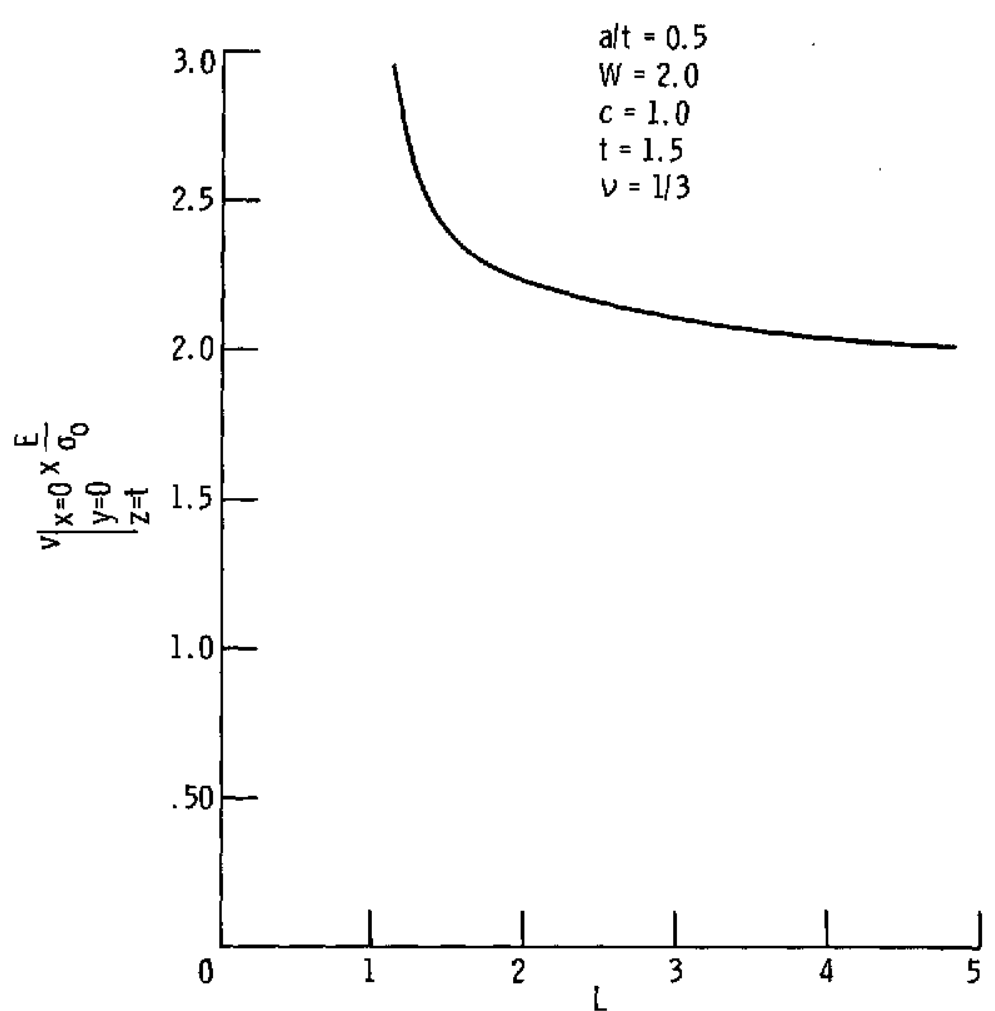

Figure 7. - Maximum crack opening displacement variation with bar length for a rectangu lar bar under uniform tension. 

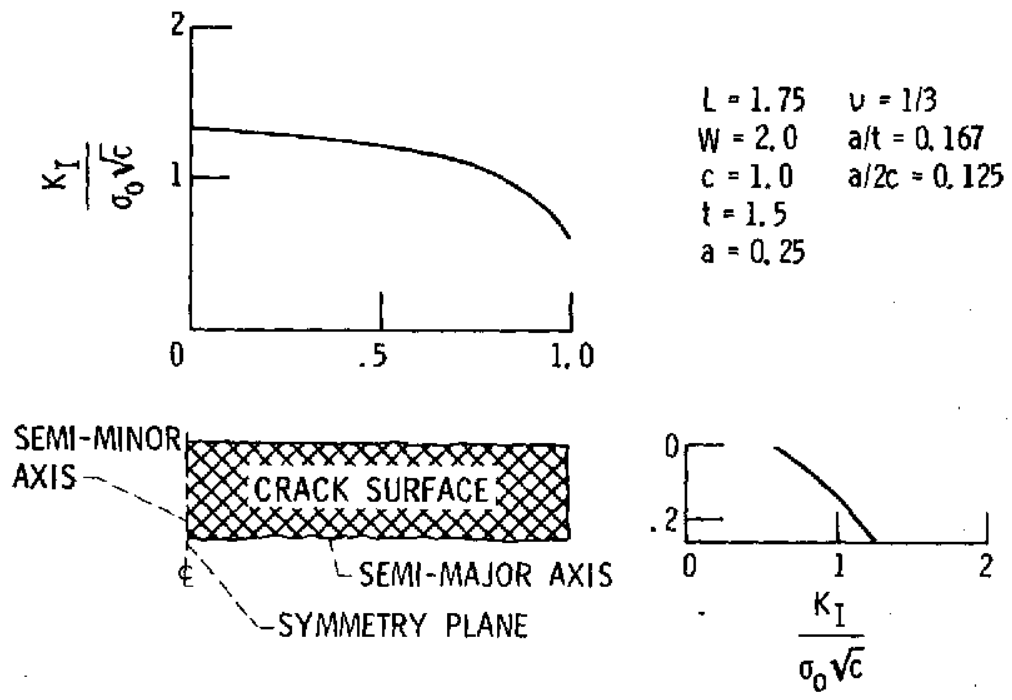

Figure 8. - Variation of stress intensity factor $\mathrm{K}_{\mathrm{I}}$ along the crack periphery for a bar under uniform tension containing a rectangular surface crack.
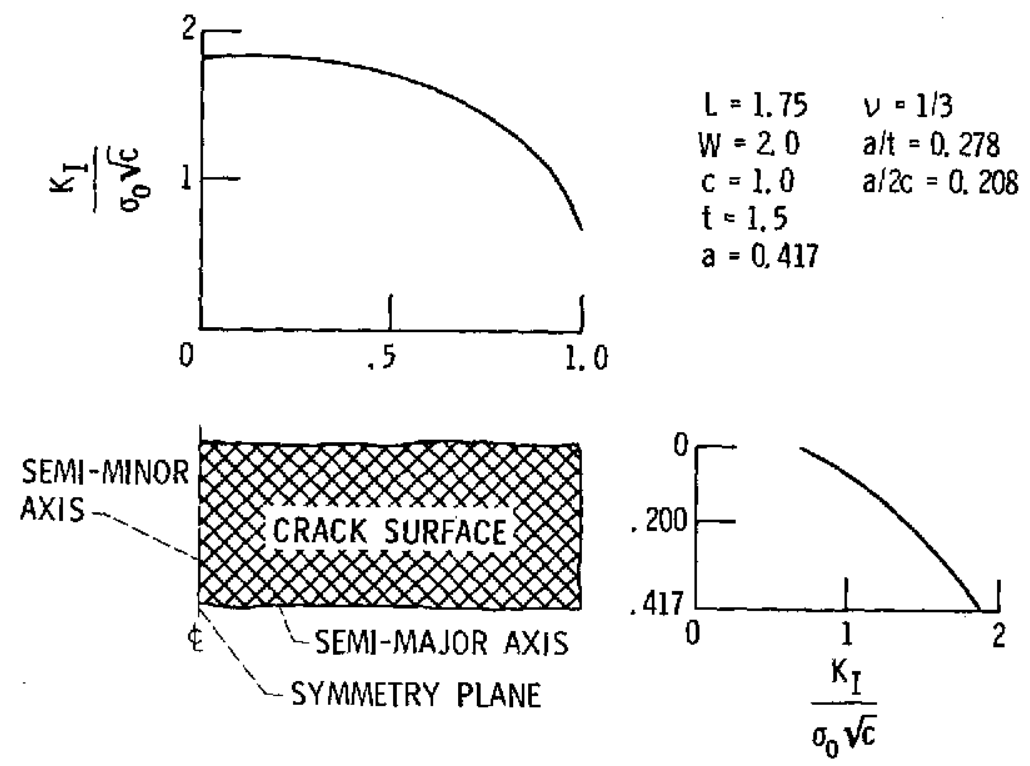

Figure 9. - Variation of stress intensity factor $K_{I}$ along the crack periphery for a bar under uniform tension containing a rectangular surface crack. 

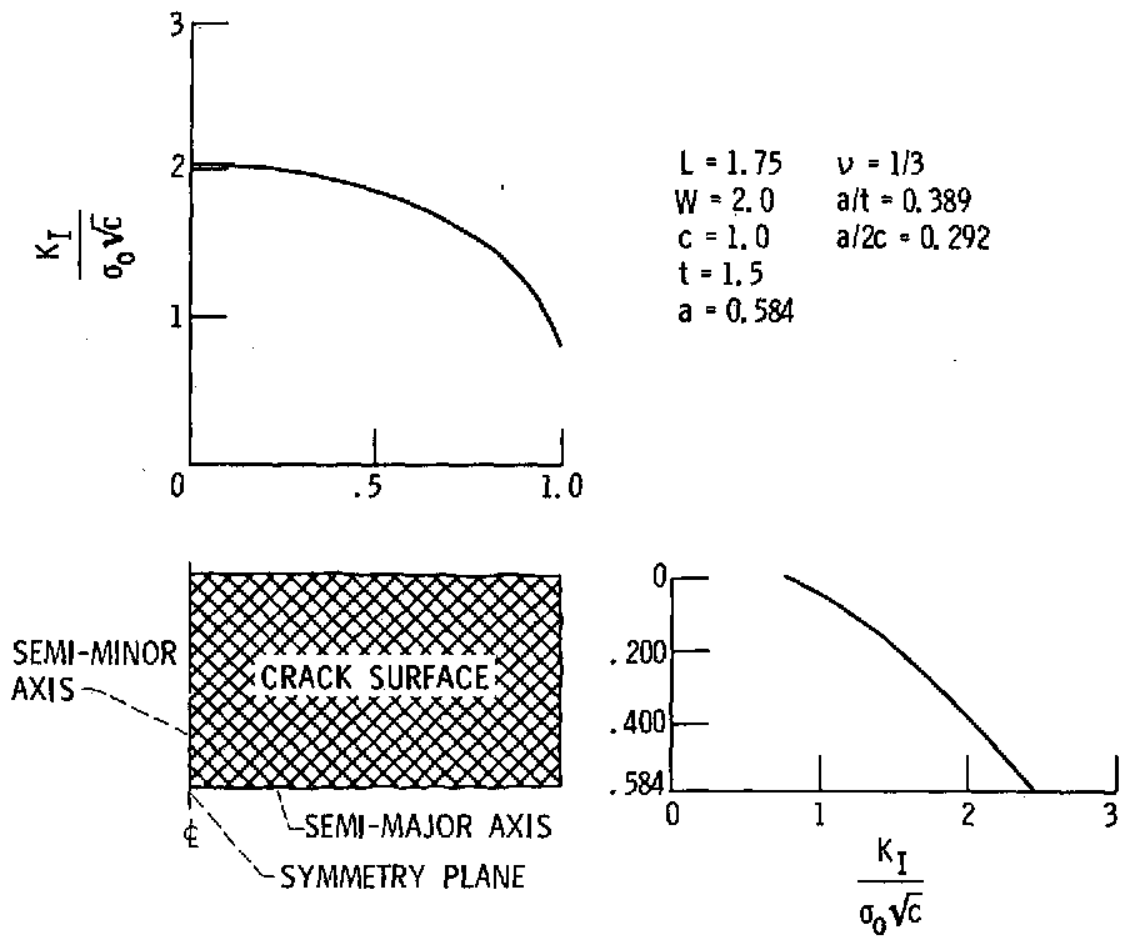

Figure 10. - Variation of stress intensity factor $\mathrm{K}_{\mathrm{I}}$ along the crack periphery for a bar under uniform tension containing a rectangular surface crack. 


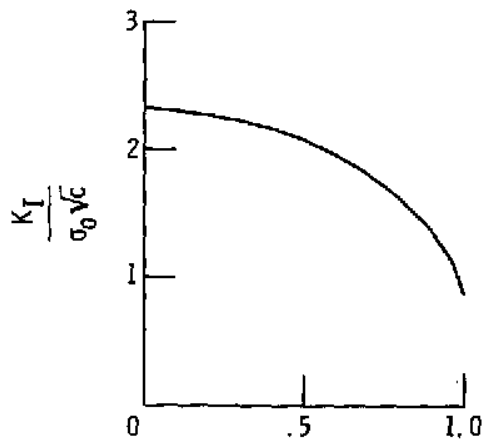

$L=1.75 \quad V=1 / 3$

$W=2.0 \quad \mathrm{a} / \mathrm{t}=0.611$

$C=1.0 \quad a / 2 C=0.458$

$t=1.5$

$a=0.917$
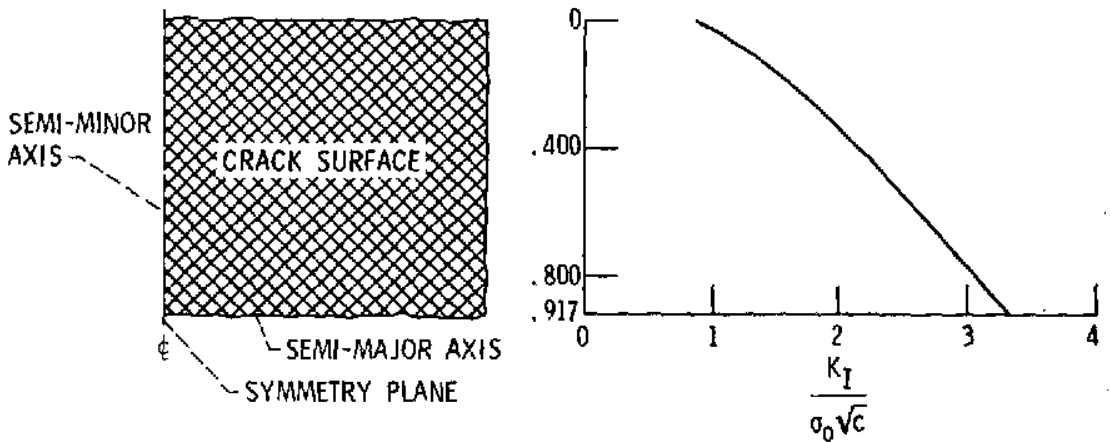

Figure 12, - Variation of stress intensity factor $K_{1}$ along the crack periphery for a bar under uniform tension containing a rectangular surface crack.

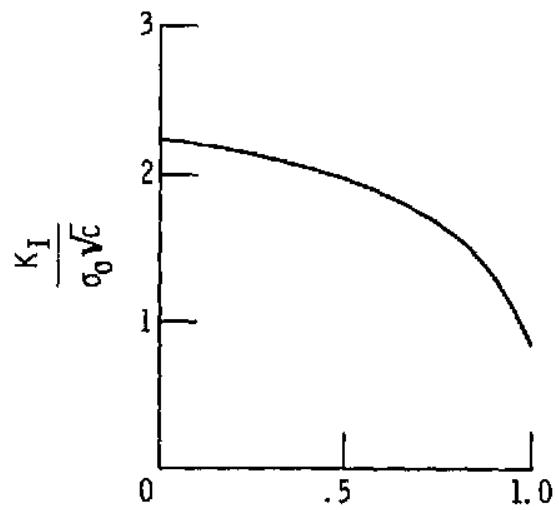

\section{$L=1.75 \quad v=1 / 3$}

$W=2.0 \quad$ a/t $=0.50$

$c=1.0 \quad a / 2 c=0.375$

$t=1.5$

$a=0.75$
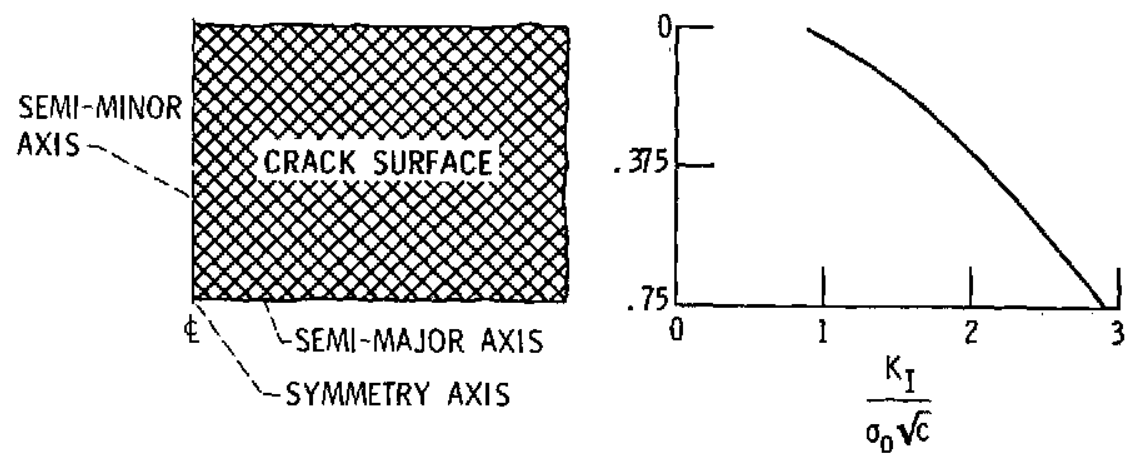

Figure 11. - Variation of stress intensity factor $K_{I}$ along the crack periphery for a bar under uniform tension containing a rectangular surface crack. 


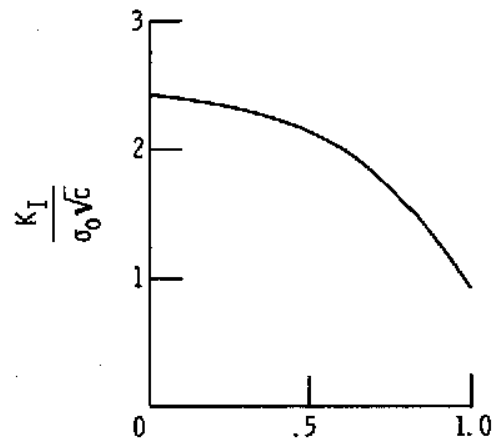

$$
\begin{array}{ll}
L=1.75 & v=1 / 3 \\
W=2.0 & a / t=0.722 \\
C=1.0 & a / 2 c=0.504
\end{array}
$$

$t=1.5$

$a=1.083$

$\stackrel{0}{\sigma}$

SEMI-MINOR

AXIS -
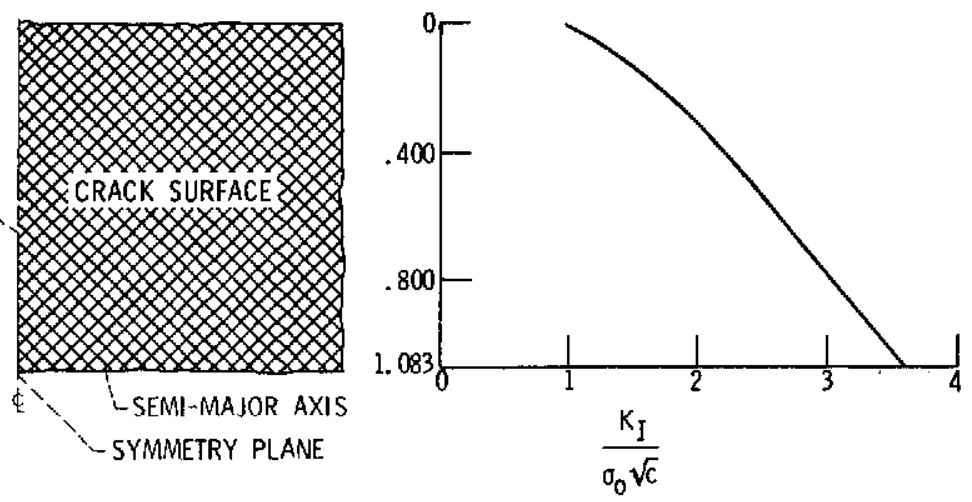

Figure 13. - Variation of stress intensity factor $K_{I}$ along the crack periphery for a bar under uniform tension containing a rectangular surface crack. 

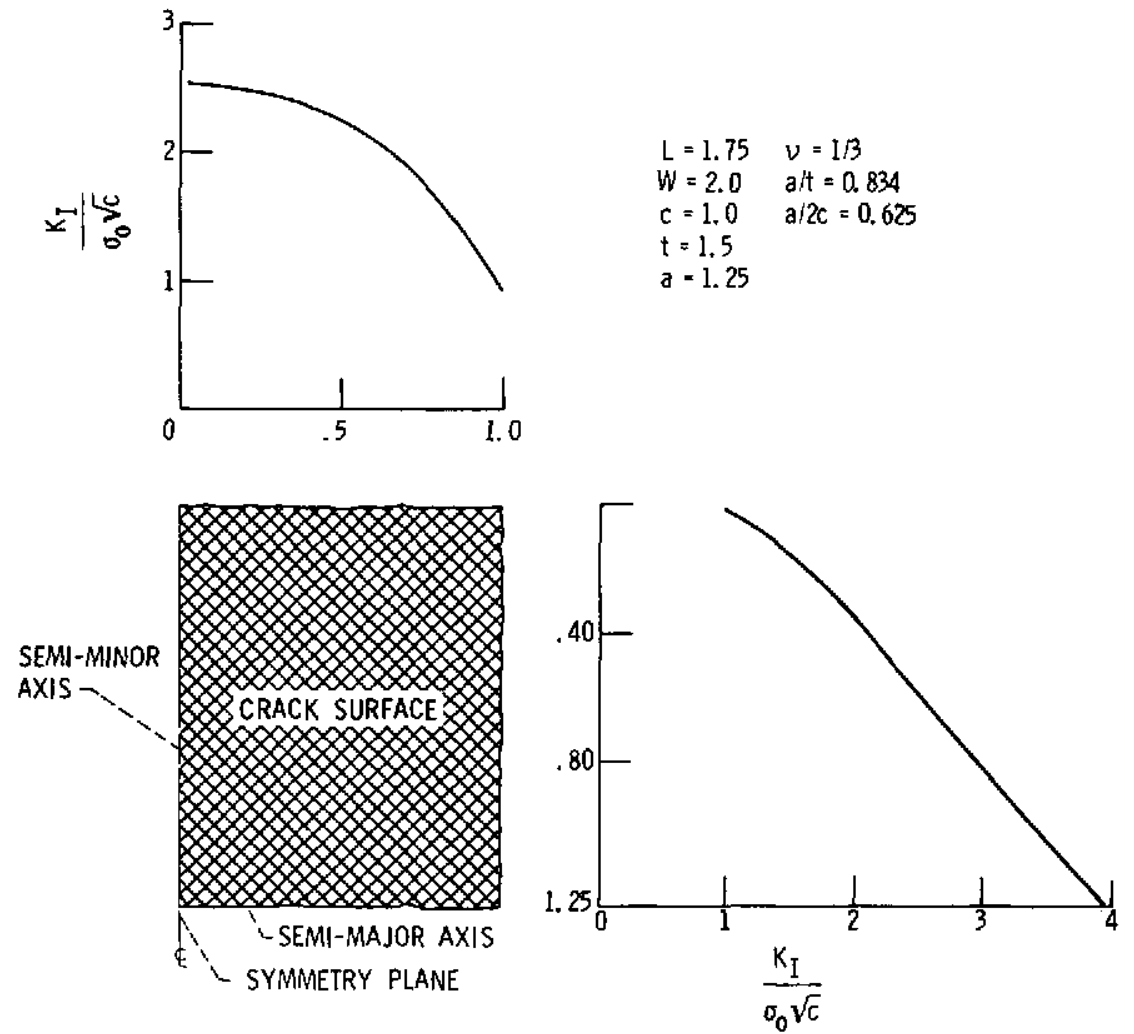

Figure 14, - Variation of stress intensity factor $\mathrm{K}_{\mathrm{I}}$ along the crack periphery for a bar under uniform ten sion containing a rectangular surface crack.
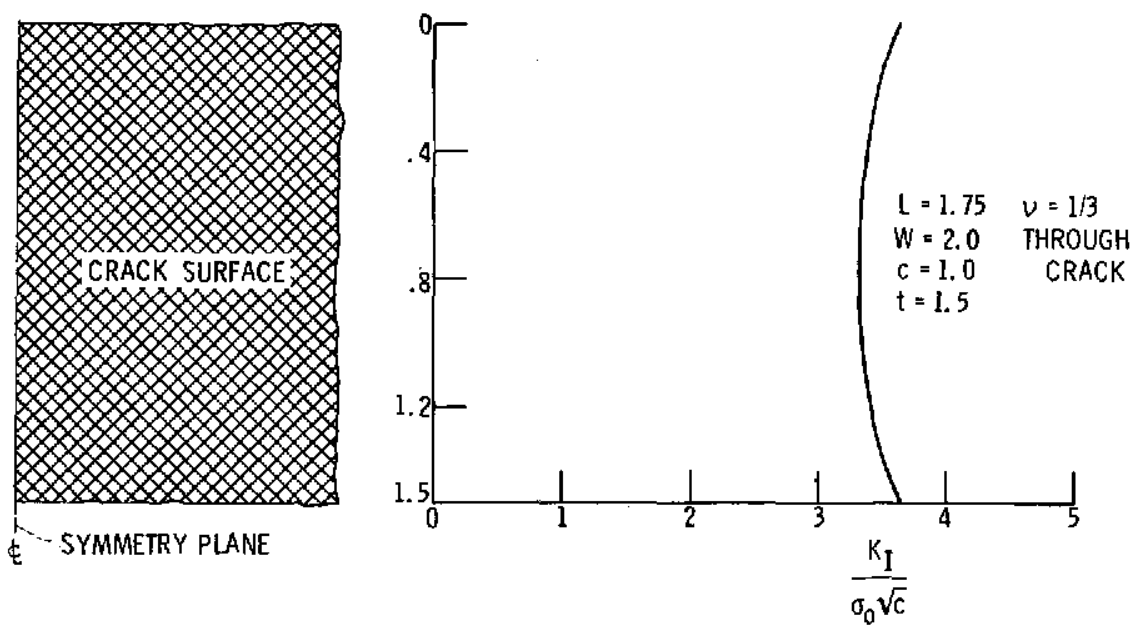

Figure 15. - Variation of stress intensity factor $\mathrm{K}_{\mathrm{I}}$ along the crack periphery for a bar under uniform tension containing a central through-thickness crack. 


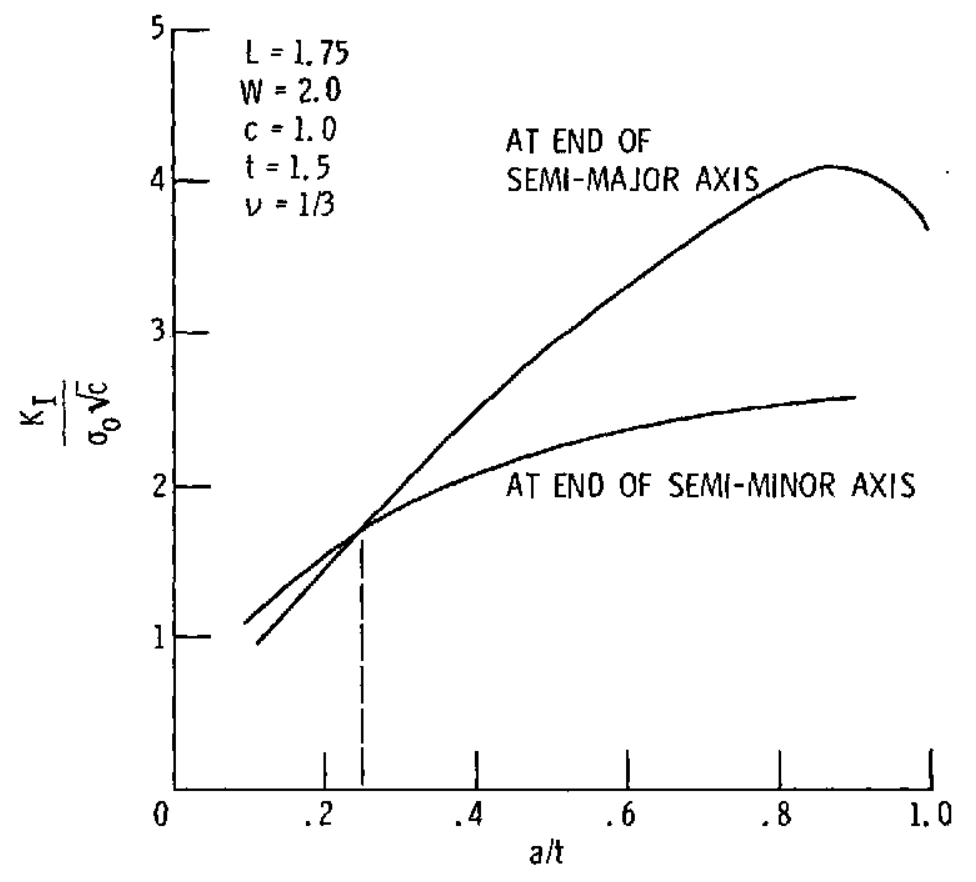

Figure 16. - Stress intensity factor variation with crack depth for a bar under uniform tension containing a rectangular surface crack.

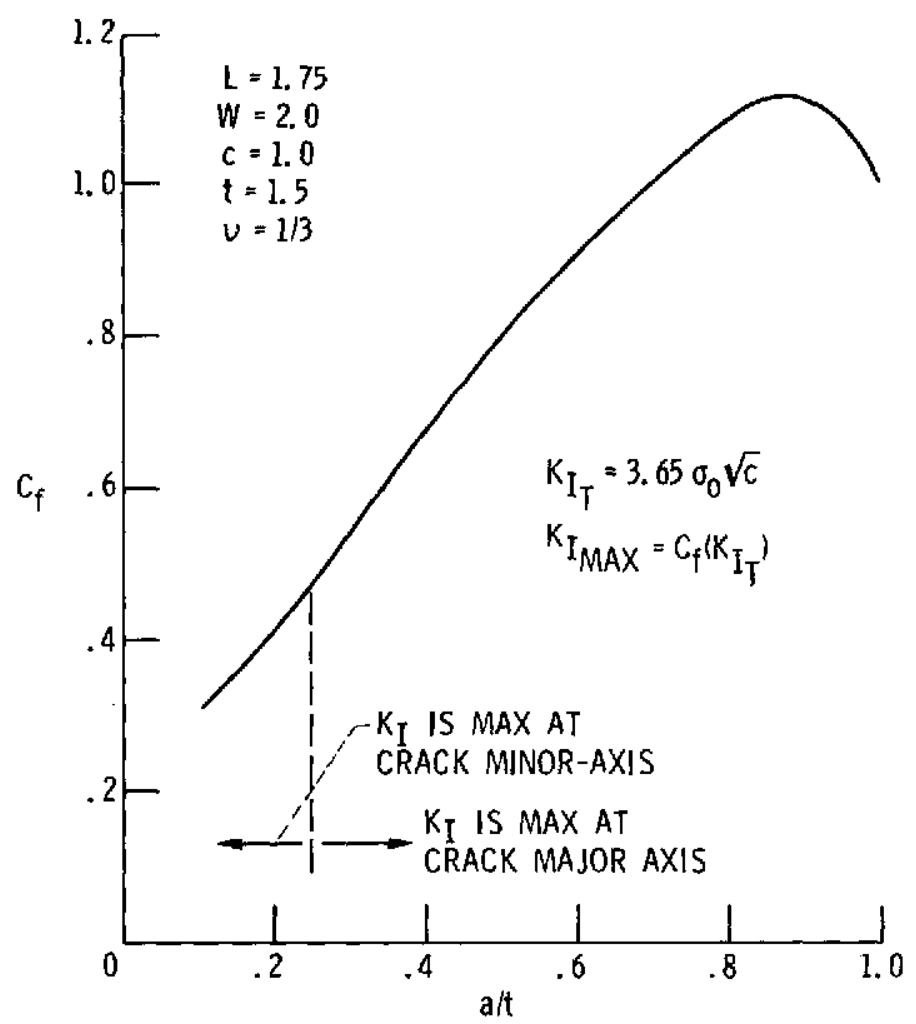

Figure 17. - Surface crack correction factor variation with crack depth for a bar under uniform tension. 


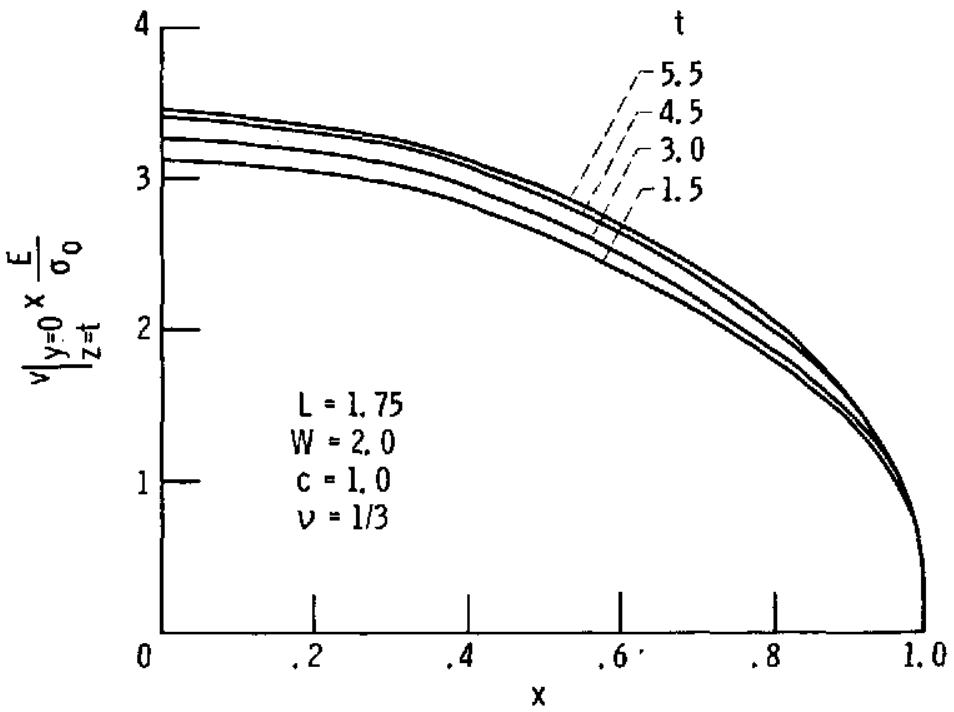

Figure 18. - Surface crack opening displacement variation as a function of bar thickness for a center cracked rectangular bar under uniform tension.

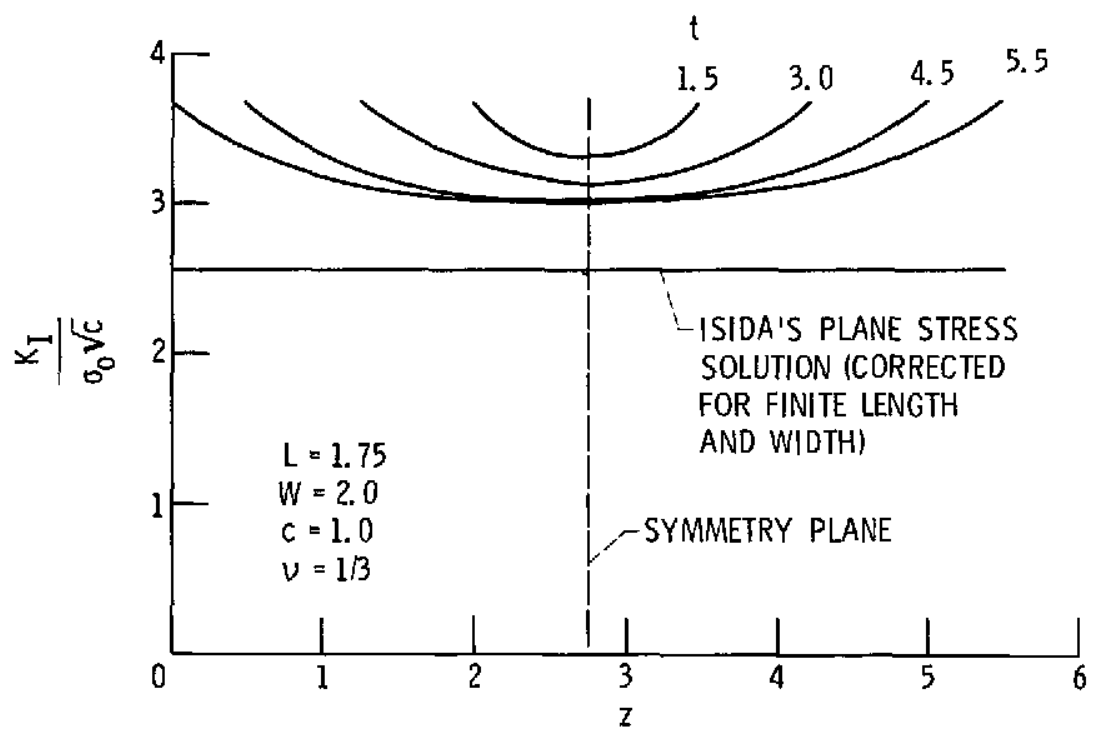

Figure 19. - Stress intensity factor variation as a function of bar thickness for a center cracked rectangular bar under uniform tension. 